\title{
Peer-Prompted Engineering Design: How Do Adolescents Interact and Strategize?
}

Kristin M. Strong, Oenardi Lawanto, \& Amy Wilson-Lopez

\begin{abstract}
Engineering design was integrated into $\mathrm{K}-12$ science education in the Next Generation Science Standards (NGSS Lead States, 2013), but teaching design remains a challenge for educators. Design problems are ill-defined, illstructured, and complex problem-solving tasks. Their solutions require creativity and recursive, metacognitive processes that cannot be taught with simple algorithms. Moreover, adolescents do not demonstrate fully developed metacognitive skills because they are undergoing profound developmental changes. In this comparative case study, we explored how peer-delivered metacognitive prompts supported adolescents during a design challenge. We investigated how scripted prompts sparked reflection and stimulated design changes and identified which prompts were most effective. We also observed four interaction patterns between paired peers. The interaction patterns influenced the quantity of design changes and shaped the strategies that students used during revisions.
\end{abstract}

Keywords: adolescents, collaborative learning, engineering design, metacognition, middle school, prompts

In 2009, the Committee on Engineering Education and the National Research Council (Katehi, Pearson, \& Feder) issued their report, Engineering in K-12 Education: Understanding the Status and Improving the Prospects, which outlined the benefits of K-12 engineering education to science, technology, engineering, and mathematics (STEM) education. In addition to widening the STEM pathway and improving technology literacy, the committee believed that engineering education could act as a catalyst to integrate all the STEM disciplines and make them more effective.

The committee also gave general principles for the implementation of engineering education. Their first key principle was that " $\mathrm{K}-12$ engineering education should emphasize engineering design" (Katehi et al., 2009, p. 4). In 2013, developers of the Next Generation Science Standards (NGSS Lead States, 2013) implemented the directive and elevated engineering design to the level of scientific inquiry.

Teaching design, however, presents a challenge to educators because of the fundamental nature of design: 
- Design is an ill-structured, ill-defined, and complex problem-solving task (Christiaans \& Venselaar, 2005; Cross, 2004; Goldschmidt \& Weil, 1998);

- Design is a recursive feedback process of "action and reflection" (Christiaans \& Venselaar, 2005, p. 217);

- Design requires the regulation and integration of multiple forms of knowledge, and it relies heavily on metacognition (Christiaans \& Venselaar, 2005; Jonassen, 2000); and

- Design requires the simultaneous "“co-evolution' of the problem space and the solution space" (Maher, Poon, \& Boulanger, 1996; as cited in Dorst \& Cross, 2001, p. 434; see also Cross, 2001, 2004).

Because of these characteristics, design problems do not lend themselves to simple solutions via algorithms that can be easily implemented in a K-12 classroom (Goldschmidt \& Weil, 1998; Jonassen, 2000). Although educational researchers may study the "science of design," Cross (2001) argues that a "design science" with logical, systematic, and rigid algorithms for solving design problems is not congruent with the process of design. Instead, the pedagogy for solving design problems requires a more reflective and creative approach that emphasizes metacognitive skills to help students "know what they know" and regulate their knowledge (Lawanto, Butler, Cartier, Santoso, Goodridge, et al., 2013; Lawanto, Butler, Cartier, Santoso, Lawanto, et al., 2013; Pintrich, 2002).

Metacognition must be emphasized because design problems and other illstructured problems are dominated by metacognitive processes (Christiaans \& Venselaar, 2005; Jonassen, 2000). During the design process, students must repeatedly identify and define subproblems, generate solutions, and then return back to the original top-level problem (Sheppard, Macatangay, Colby, \& Sullivan, 2009). Thus, design is distinctly nonlinear and requires the awareness, management, and integration of many forms of knowledge through metacognitive skills (Christiaans \& Venselaar, 2005; Jonassen, 2000; Mawson, 2003).

Educational researchers (Lawanto, Butler, Cartier, Santoso, Goodridge, et al., 2013; Lawanto, Butler, Cartier, Santoso, Lawanto, et al., 2013; Luo, 2015; Wilson, Smith, \& Householder, 2014) have shown, however, that students' metacognition may be insufficient for them to engage successfully in all phases of the design process. Cognitive neuroscientists (Casey, Jones, \& Hare, 2008; Choudhury, Charman, \& Blakemore, 2008) have also reported that adolescents have immature metacognitive skills because of profound developmental brain changes. Consequently, a need exists to support adolescent metacognitive skills in the context of design. One promising method of support is prompting. 


\section{Invoking Metacognition}

\section{Literature Review}

Metacognitive skills are considered to be more difficult to develop than cognitive skills (Vos \& de Graaff, 2004). Lin (2001) noted that students do not automatically employ their metacognitive skills unless they are actively encouraged to do so. Peteranetz (2016) developed a taxonomy of metacognitive instruction that subdivided instructional methods into two broad categories: implicit and explicit. The explicit approaches identified were direct instruction and teaching benefits. The implicit approaches were modeling (when an instructor shows metacognition in action) and prompting (when students are encouraged or reminded to engage in metacognition). This study adopted the implicit prompting approach.

\section{Delivering Prompts via Peer Tutoring}

Prompts can be delivered in a myriad of ways: through teachers, in written questions (on paper or on-screen), or via peers. Prompts delivered via peers can evolve into peer tutoring, a form of collaborative learning, and take advantage of natural brain development. During adolescence, peers become especially important and influential because of changes that take place in three regions of the brain (Choudhury, Blakemore, \& Charman, 2006). Peer tutoring capitalizes on the natural affinity of adolescents for peer interaction.

During peer tutoring, students may question, assess, explain, and give feedback to their peers. These interactions between peers provide multiple opportunities for invoking metacognition (Choi, Land, \& Turgeon, 2005). During explanations, students must organize their knowledge and express it in ways that a peer can understand, making explicit what they know and do not know (Bargh \& Schul, 1980). They may discover holes in their knowledge when they cannot explain something fully or when they realize that something they have said does not make sense. Explanations to peers, like self-explanations, are piecewise events that provide many opportunities for structuring knowledge, revising mental models, or repairing misconceptions (Chi, De Leeuw, Chiu, \& LaVancher, 1994).

Questions that arise during peer tutoring are another way to stimulate metacognition. Questions may be provoked by inconsistencies between incoming knowledge and existing knowledge. Questions can act as an "epistemic probe" or a "heuristic tool" (Chin \& Osborne, 2010, p. 884), sorting out what a student knows and does not know and supporting argumentation. Like explanations, questions also make visible a student's knowledge and reasoning, setting the stage for peers to co-construct knowledge by offering confirmations or corrections of knowledge, or by filling in gaps. Questions are essential to developing the metacognitive skills involved in critical reasoning (Chin \& Osborne, 2008, 2010). 
The feedback or assessment that may arise from a peer during peer tutoring is also instrumental in promoting metacognition. Many researchers (Butler \& Winne, 1995; Greene \& Azevedo, 2007; Labuhn, Zimmerman, \& Hasselhorn, 2010) have described how feedback from an external source, including peers, sets in motion self-regulatory processes. For example, Butler and Winn (1995) described how feedback can act as a "catalyst" for metacognitive activities such as monitoring.

\section{Enhancing Peer Tutoring Efficacy}

Peer tutoring efficacy can be enhanced through structure or guidance (Ismail \& Alexander, 2005; King, Staffieri, \& Adelgais, 1998; Roscoe \& Chi, 2007; Topping, 2005). Researchers have observed that without structure, peer tutors often resort to low-level, "knowledge-telling" rather than "knowledgebuilding" explanations. Or they ask only low-level, factual knowledge questions. Structuring or guiding a peer tutoring session with prompts is one way to elevate the quality of the peer tutoring and to reach higher knowledge construction (King et al., 1998; Lin, 2001; Roscoe \& Chi, 2007).

\section{Purpose and Objectives}

The purpose of this research was to explore how scripted, peer-delivered prompts invoked metacognition in middle school designers. Our primary objective was to see how the prompts encouraged paired students to make design changes - to see how paired students interacted in a script-guided environment - and what metacognitive strategies they used to make changes. Additional objectives were to see which prompts and which types of peer-topeer verbal phenomena were most effective at inciting design changes.

\section{Context of the Study}

Our study focused on the early design process. In early design, students first interpret the design problem and create a design brief, a written document capturing essential design information, in which students set their goal, criteria (features), and constraints (Cross, 2000). Then, they can begin generating design solutions (sketches).

\section{Sampling}

Reflecting the desire to develop a pragmatic intervention, we conducted the study in a public middle school in the Western United States with the potential for variation in STEM exposure and socioeconomic status. We employed a mixed, "purposeful" (Patton, 1990) sampling strategy, selecting participants using (a) typical sampling and (b) criterion sampling by grade and course. Students received token compensation (\$10) for their participation.

The research site was a career and technical education classroom with 32 seventh-grade students. Because career and technical education was a required 
course for all seventh graders, the demographics of the classroom likely reflected those of the school: approximately $61.1 \%$ Caucasian, $29.3 \%$ Hispanic, $3.8 \%$ Asian, $1.7 \%$ African American, $1.9 \%$ Native American, $0.7 \%$ Pacific Islander, $1.5 \%$ two ethnicities, and 23\% English language learners (school demographics came from the National Center for Education Statistics Common Core of Data for the 2016-2017 school year). Sixty percent of the students received free or reduced-price school lunch.

\section{Research Protocol}

Over the course of three days, a graduate student researcher introduced students to the engineering profession as well as the concepts of design, design briefs and sketches, and animal enrichment. As part of the curriculum, all 32 students engaged in a design-challenge activity during which data were collected from the 21 students who had agreed to participate in the study.

The design challenge was based on the $\mathrm{K}-12$ engineering fair project The Cat's Meow: Designing an Enrichment Toy, developed for the nonprofit educational organization Science Buddies in 2008 (https://www.sciencebuddies.org/science-fair-projects/projectideas/Zoo_p051/zoology/cat-enrichment-toys).

The design challenge was chosen because animals and pets appeal to a wide variety of children and are motivating (Chen, Chou, Deng, \& Chan, 2007). In addition, we felt that this challenge would yield designs with great variability, as opposed to challenges in which students designed for the same user or users.

On Day 1, students were told to select a zoo animal or pet and do background research to find out about their chosen animal's characteristics. On Day 2, students worked independently and developed an initial design brief and sketch of their toy.

On Day 3, each student was paired with a peer. Using scripts with metacognitive prompts, each student presented his or her initial design to a peer partner. The scripts guided students to ask each other about how their designs worked and inquired about design strengths and weaknesses. One script (read by a presenting student's partner) contained seven questions prompting the presenting student to explain his or her design. The other script (read by the presenting student) contained two questions asking his or her partner for feedback. After both students had presented their designs and received feedback, they worked on their own redesigns while sitting together as a pair. 


\section{Methodology}

The study was conducted using a qualitative methodology, specifically a comparative case-study approach in which comparisons were made within and across multiple, comparable, "information-rich" (Patton, 1990) cases to look for patterns (Levy, 2008; Wilson et al., 2014). Within the study, a case was defined as a pair of seventh-grade students engaged in a design-challenge activity guided by peer-delivered metacognitive prompts.

\section{Data Sources}

In each case, we focused on the students' verbal responses to prompts and their subsequent design revisions. Therefore, the data sources were: (a) the students' conversational turns, which were audio recorded; (b) their written design briefs (initial and revised); and (c) their sketches (initial and revised).

\section{Data Analysis}

We analyzed the design changes between the revised and initial design briefs and sketches quantitatively and qualitatively. Quantitatively, we looked at how many design changes were made. Qualitatively, we looked at how the criteria and constraints changed between the initial and revised designs. For example, was a new criterion simply altered from the original one, making it more refined? Was a new criterion a completely new, enhanced feature in the design? Was a new or altered criterion critical — not just nice to have but essential to its function? How did labeling change? How did sketch detail change? All qualitative attributes were coded.

The next step was to analyze the verbal interactions between student pairs while the students read and responded to the prompts and then worked on their redesigns. Two researchers coded the transcripts of student conversations using a codebook (Strong, 2018) containing definitions of explanations (simple or user-centered), questions, feedback, and other codes. The researchers engaged in rounds of coding and codebook modifications until an interrater reliability statistic (Cohen's kappa) greater than 0.85 was achieved (Hruschka et al., 2004).

The final step in the data analysis was to link the design changes (analyzed design briefs and solution sketches) to the analyzed and coded transcripts (e.g., questions, explanations, or feedback) to determine how the design changes arose. Linking the design changes to the code categories created a chain of evidence (Yin, 2009) and answered the research objective regarding how the students made design changes (i.e., the metacognitive strategies that they used). We created link maps for each one of a student's design changes and for each student participant, as shown in Figure 1. 


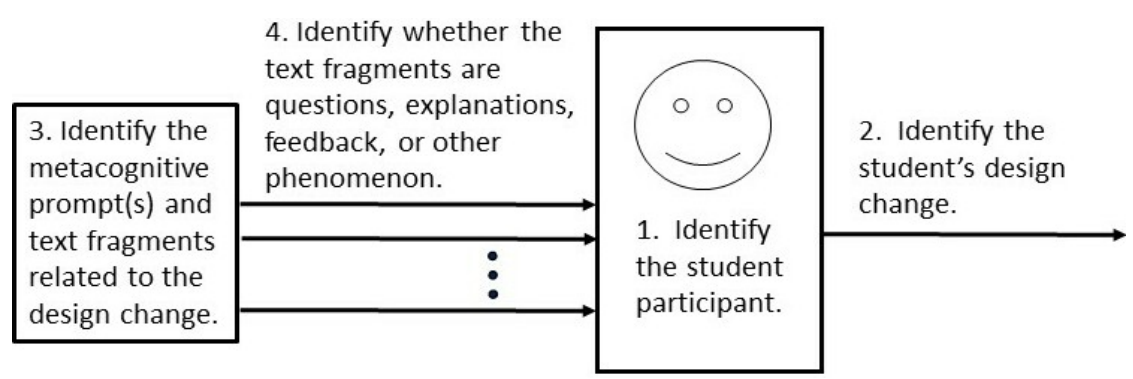

Figure 1. Process for mapping links between a student's design change and peer-to-peer verbal phenomena.

\section{Comparing Within and Across Cases}

In comparative case studies, comparisons are made within and across multiple cases. Researchers analyze each case individually and then analyze the entire set of cases, looking for patterns of similarities and differences in the phenomenon under study (Goodrick, 2014; Wilson et al., 2014). Results from comparative case studies are considered to be more robust and compelling than single case studies (Yin, 2009), enhancing transferability (Polit \& Beck, 2010).

We first analyzed coded link maps for each pair of students, looking for patterns of interactions (e.g., questions, explanations, or feedback) that drove design revisions. We then synthesized patterns across all case pairs and observed distinct interaction patterns that influenced how the designs came to be modified.

\section{Limitations}

The study's characteristics - its methodology, sampling, and curriculumimposed limitations. As a qualitative study, the findings may have variable interpretations. Seven student participant pairs (four male and three female) fully completed the entire 3-day curriculum. The time in which each participant engaged with the research curriculum, surveys, and design activity was limited to approximately 2 hours total. We have attempted to provide a "thick description" of the cases (Strong, 2018) so that readers may determine for themselves the transferability of the findings to adolescent populations of their interest (Polit \& Beck, 2010).

\section{Findings for Peer Interactions}

Four interaction patterns emerged from the analysis of the case pairs. The patterns are depicted in Figure 2, which illustrates, metaphorically, the dynamics of the peer-to-peer interactions during the design challenge. The climbers in each drawing represent the pair of students in each case. The challenge to climb the mountain represents the redesign task. Note that in two instances, the climbers are at the same approximate level on the mountain, representing 
seemingly similar abilities in metacognitive practices. In two other patterns, the climbers are at different levels on the mountain, representing disparate metacognitive practices. Also, if the climbers are on the same side of the mountain, that indicates they are following a similar design path with similar design features; however, if they are on opposite sides, that illustrates an independent design path with independent design features. The rope or flag in three drawings is a representation of social or emotional support. Note that in one interaction pattern (Soloists), there is none.

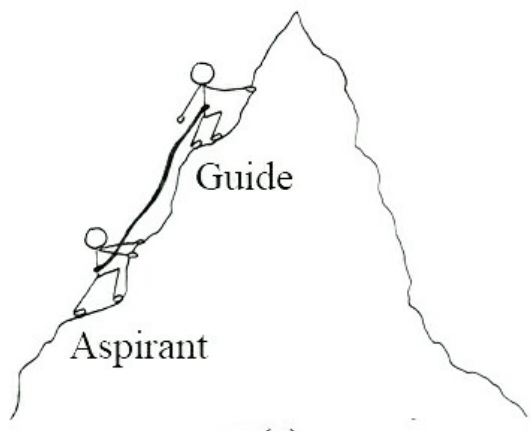

(a)

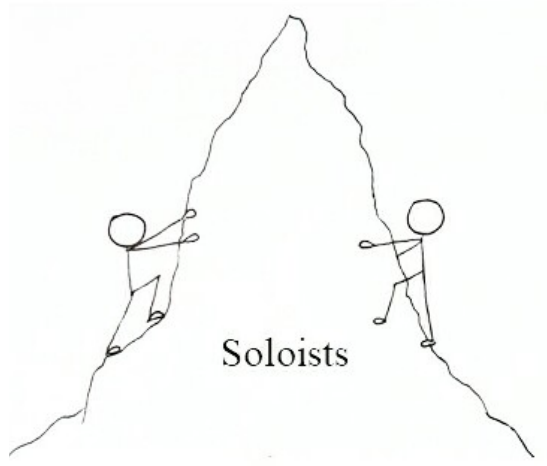

(c)

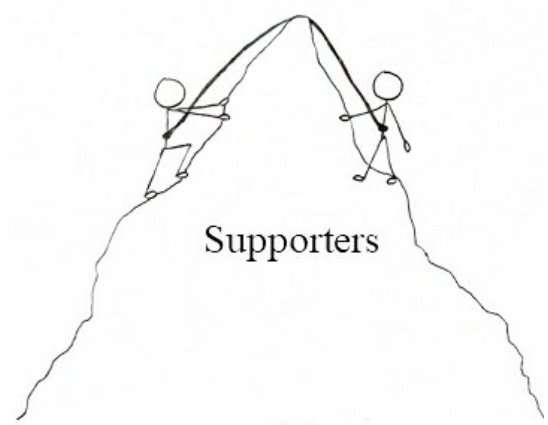

(b)

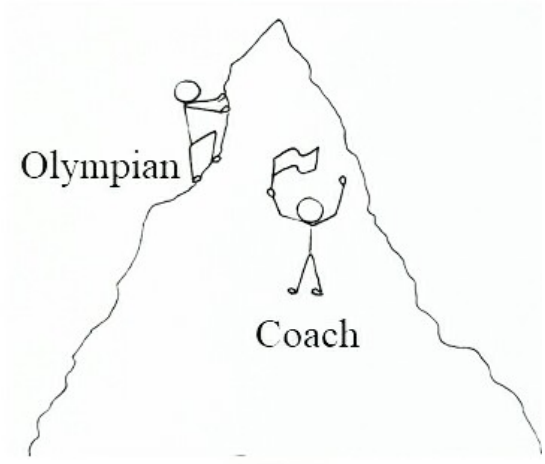

(d)

Figure 2. Observed peer interaction patterns during the design challenge: (a) Guide and Aspirant, (b) Supporters, (c) Soloists, and (d) Olympian and Coach. 


\section{The Guide and the Aspirant}

One pair of boys and one pair of girls were exceptionally good at eliciting design changes in both partners. In each case, the pair had a student who was a Guide - a self-regulated learner who used metacognitive strategies to guide the redesign of both students.

The partner to the Guide was a student who was an Aspirant — a student who was unsure but very motivated to improve. The motivation came from observing the Guide's design and redesign. As depicted in Figure 2a, the students were linked together and followed a similar redesign path. The pairing of a Guide with an Aspirant was a highly effective and dynamic combination, yielding the most design changes per pair.

The metacognitive strategies used by the Guide partner included vocalized private speech, questioning (e.g., "What would make this better?"), checking task instructions, and explanations that contained simulations of how the user would interact with the design or what the user was thinking or feeling. The metacognitive strategies used by the Aspirant partner included explanations (with and without simulations) and requests for feedback. After redesigning, the Aspirant's design became more like the Guide's with similar design features.

The Guide and Aspirant cases are shown in Figures 3 and 4 for the male and female pairs, respectively. The top row in each case shows the initial designs for the Guide (on the left) and for the Aspirant (on the right). The second row shows the revised designs after the student pairs have read and responded to the scripted prompts and then interacted informally.

For the boys, the Guide, Leo, ${ }^{1}$ designed an enrichment toy - a play areafor cats, and the Aspirant, Javier, designed a toy for dogs. Note that Leo's designs contain many "stations" where cats could have different forms of entertainment or pleasure (e.g., a feeding station, a napping room, a viewing room, and a slide).

Although Javier's initial design was solid (a squeaky ball suspended from a weighted arm), the transcript revealed that he was dissatisfied with it after seeing his partner's design. For example, when Leo read the prompt asking Javier what he thought was the best part of his design, Javier responded glumly that he didn't know. And later, Javier asked Leo for support, saying, "I don't even know what to put in mine." Javier ended up abandoning his initial design completely and instead, with Leo's support (e.g., "You should probably have a shoe room. A room full of shoes. Dogs love shoes"), made a play area for dogs with different stations (e.g., a ball room, a sock room, a shoe room, and a feeding station). Javier's redesign features echoed Leo's. The boys followed a similar redesign path.

\footnotetext{
${ }^{1}$ All names are pseudonyms.
} 


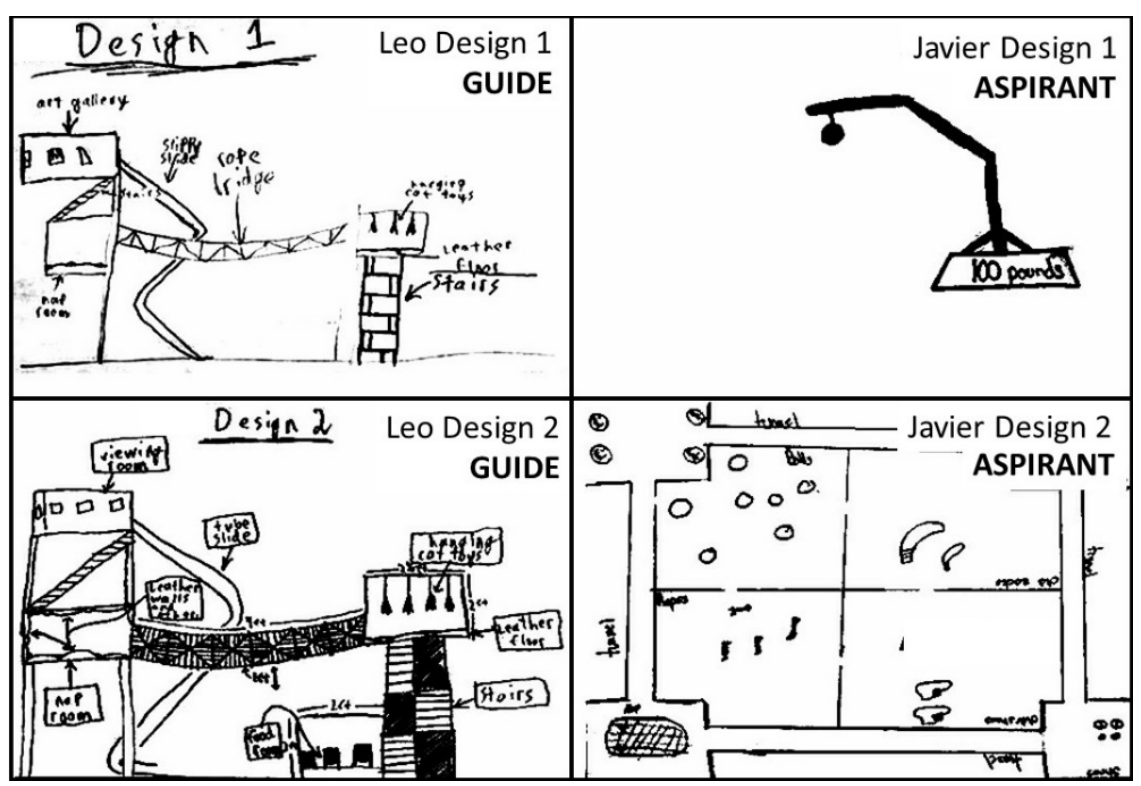

Figure 3. Initial (top row) and revised (bottom row) sketches from the Guide and Aspirant boys.

For the girls, the Guide, Jade, designed an enrichment toy for hippos-an underwater rattle that was powered by waves. Like the male Guide, Leo, in the previous case, Jade displayed excellent metacognitive skills. One of Leo's metacognitive strategies was to utilize vocalized private speech, but Jade's strategies relied on questioning (e.g., "What would make it better?") and verbalizing task instructions. Like Leo, Jade displayed a strong ability to simulate how the user would interact with the design. She also imagined what the user would think or feel while using the design. "I think it will help them because they can have not just each other to play with, but something other than each other." "I think the best part is that it triggers that thing in your brain where it's like: What is that? Should I be scared of it? Should I like it? Or what?" "When the tides move, the water moves, and it makes [the beads] move. The hippos will hear it and be like, 'Wait, what is that?"'

Her initial rattle shape was a cylinder filled with beads (Figure 4, upper left). During revision, the cylinder shape changed to a sphere, and she added more noises by mixing pebbles with the beads (Figure 4, lower left). Upon receiving partner feedback to make the hippos "feel at home," she modified the toy to look "more natural" and "like a rock." In addition, upon asking herself and her partner a broad question ("Okay, what else would make it better?"), Jade thought about the safety of materials in her redesign: "For me, the biggest thing is I don't want it to decompose underwater. I don't want it to get into the hippo's 
digestive system. I don't want them to eat [plastic]. But wood softens underwater, so it could break underwater."

The Aspirant, Luisa, like Javier in the previous case, was more hesitant and unsure of the design task. Although she was never negative about her initial design in the way that Javier was, her dog toy design appeared hesitant and tentative - a small ball in the far upper left corner of the page with no detail or labeling. Her Guide partner, though, was positive and offered ample constructive feedback: "So, we could fix any flaws that it has. Or make it better in some way. Well, I think ... instead of just squeaking, it could maybe have bits of food or treats inside .... When they squeak it, it opens up and drops the treat out, and they're like, 'Oh my gosh, what was that?"

Luisa agreed that treats sounded like a good idea and wondered if the shape should be "a little bit more square." Jade affirmed her suggested shape, visualizing "a split in a tennis ball." Luisa then worried about the design (or decoration) of the toy, saying, "I'm not sure about the design." Jade offered, "Maybe it could have bones on it or something because dogs like bones." Luisa brightened and drew a bone decoration on the toy.

Jade continued to pressure Luisa gently for more changes: "Okay, is that all you want to do? Or do you want to add something else?" This questioning led Luisa to an idea that echoed one of Jade's features: "I think it would be cool to make noises once it starts rolling around." Jade enthusiastically agreed, "Yeah, that'd be cool!" So, upon interacting with her Guide partner, Luisa's redesign became expansive and sure, filling the page and even providing written details about its features (Figure 4, lower right). The Guide, Jade, led Luisa on a design path similar to her own. 


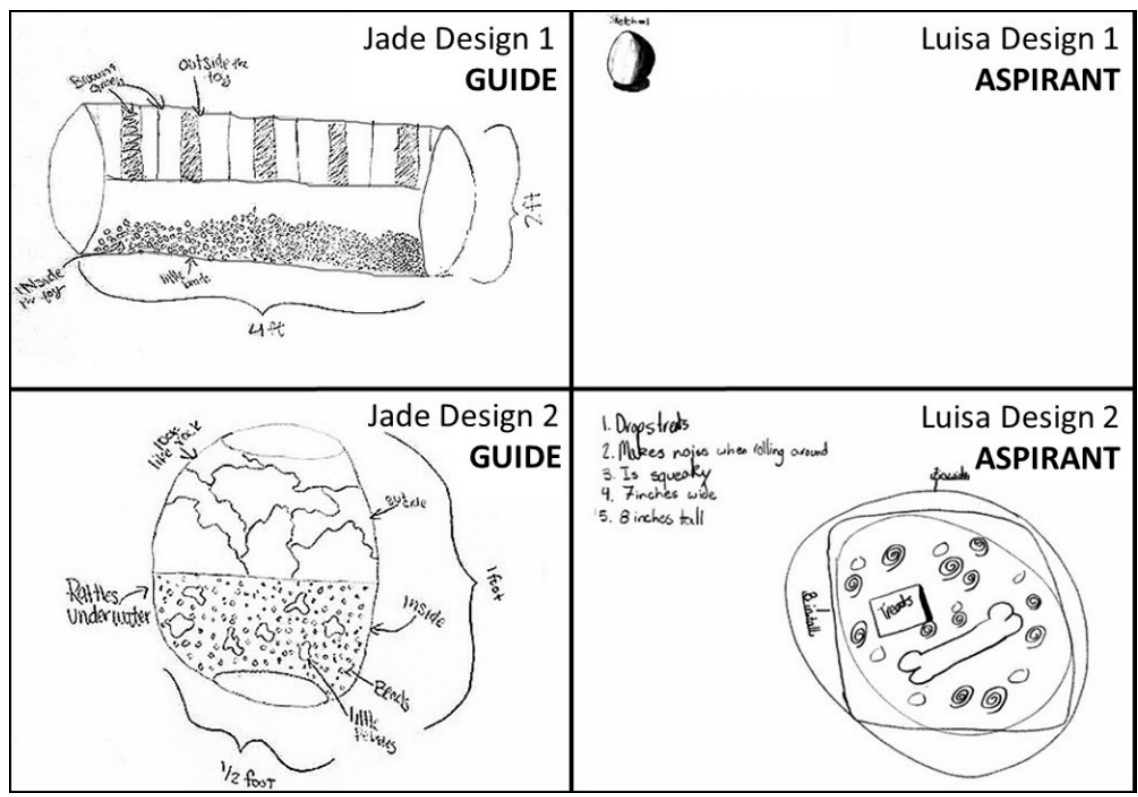

Figure 4. Initial (top row) and revised (bottom row) sketches from the Guide and Aspirant girls.

\section{The Supporters}

Three of the student pairs (two female pairs and one male pair) shared many characteristics that are illustrated by the linked climbers in Figure 2b. First, the participants in each supporter pair seemed to be at a similar level in their abilities, as depicted by the climbers being at similar heights on the mountain. Neither participant in a pair was overly dominant or appeared to have significantly greater technical or metacognitive knowledge than his or her partner.

Second, the participants were supportive. Although the participants tended to follow their own path up the mountain (their own climb up the design challenge with independent features), they did so with the support of their partner. The female pairs especially showed a great deal of mirroring of one another's comments and behavior. They were positive, encouraging, and complimentary about their partner's design. The boys were more competitive but in a teasing way. They were well matched and showed camaraderie.

Finally, for participants in these three pairs, the design changes came about through a combination of explanations about their own design and feedback from their partner. Although the number of the design changes were not as numerous as those of the Guide and Aspirant pairs, each participant made solid redesigns. There was no design fixation. 


\section{The Soloists}

Two student pairs (one male pair and one female pair) shared some characteristics with the Supporters but differed in others. Just like the Supporter pairs, the Soloist participants in each pair seemed to be well matched. No one participant was dominant. No one participant appeared to have significantly greater metacognitive or technical knowledge.

However, the Soloist pairs differed from the Supporter pairs in that they offered little or no feedback to their partner. Even when prompted by a script, or asked a spontaneous question by a partner, little or no feedback was forthcoming. In addition, they offered no complimentary (emotional) support to their partner. Therefore, design changes for each of the participants in the soloist pairs came about only (or primarily) through explanations about their own designs. This dynamic is illustrated in Figure $2 \mathrm{c}$ in which the climbers ascend the mountain up their own paths with no support rope connecting them.

\section{The Olympian and the Coach}

One male student pair had a unique dynamic. They were close friends and had worked together previously. Each was highly verbal and had an excellent ability to simulate how the user would interact with the design. One of the students, however, had significantly more technical knowledge than the other. Their unevenness led to a dynamic in which the less knowledgeable student was in awe of his partner's knowledge and design. Consequently, nearly all of the boys' redesign energy was focused on the more knowledgeable student's design. The less knowledgeable student became like a Coach to an Olympian, cheering him on and offering lots of feedback for improvements - both solicited and unsolicited. The Olympian's resulting redesign was more technical and complicated than any of the other student participants; however, the Coach never explicitly implemented his own redesign ideas. So, the redesign outcomes were uneven. The Olympian made a challenging climb to the top of a steep mountain with the support of the Coach, but the Coach remained halfway down the mountainside, never making it to the top (see Figure 2d).

\section{Findings for Prompts}

There were two sets of scripts that the paired peers read aloud to each other and responded to: One set was intended to provoke explanations to a partner, and the other set was intended to provoke feedback from a partner. For both sets of scripts, the metacognitive prompts that were most effective at inciting the students to reflect upon their designs were the "negative" prompts (which asked about design weaknesses; see Figures 5 and 6). However, "neutral" prompts (which asked about how the design worked or how the user would interact with the design without any value-laden words like weakness, improve, or best) were only slightly less effective than the negative prompts, as shown in Figure 5. "Positive" prompts (which asked about best parts of the design) were less 
effective than negative or some neutral prompts but enhanced student rapport by generating praise in most cases.

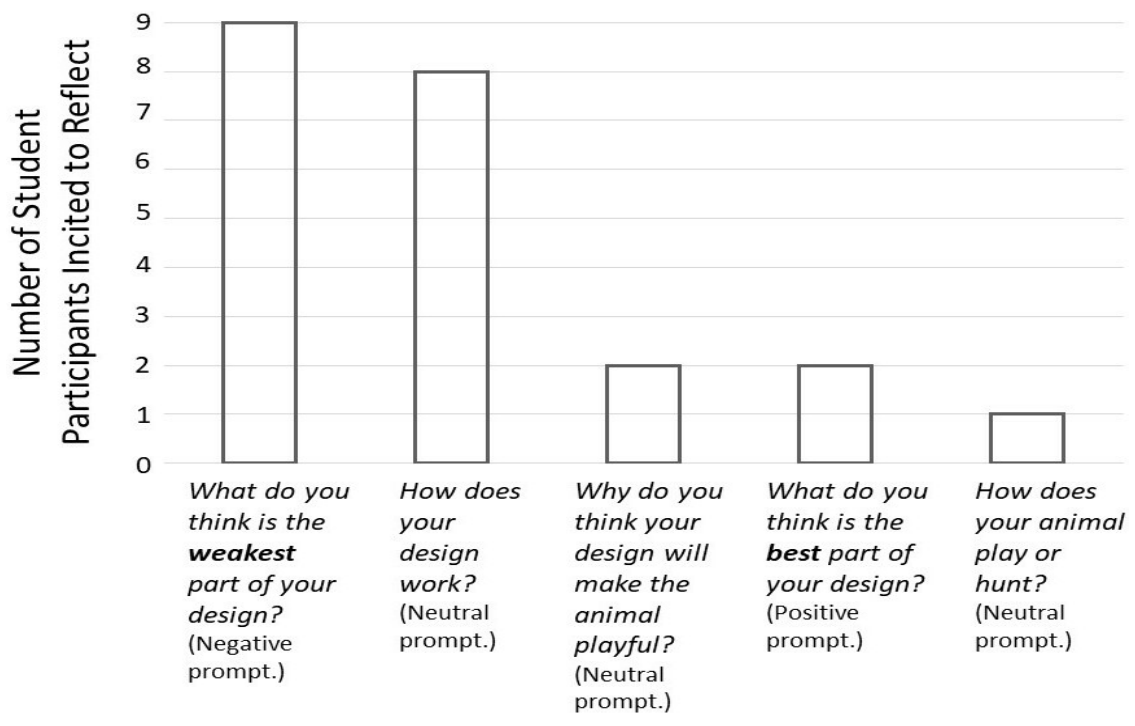

Metacognitive Prompts for Explanations

Figure 5. Number of participants who reflected on their own designs when prompted for explanations. 


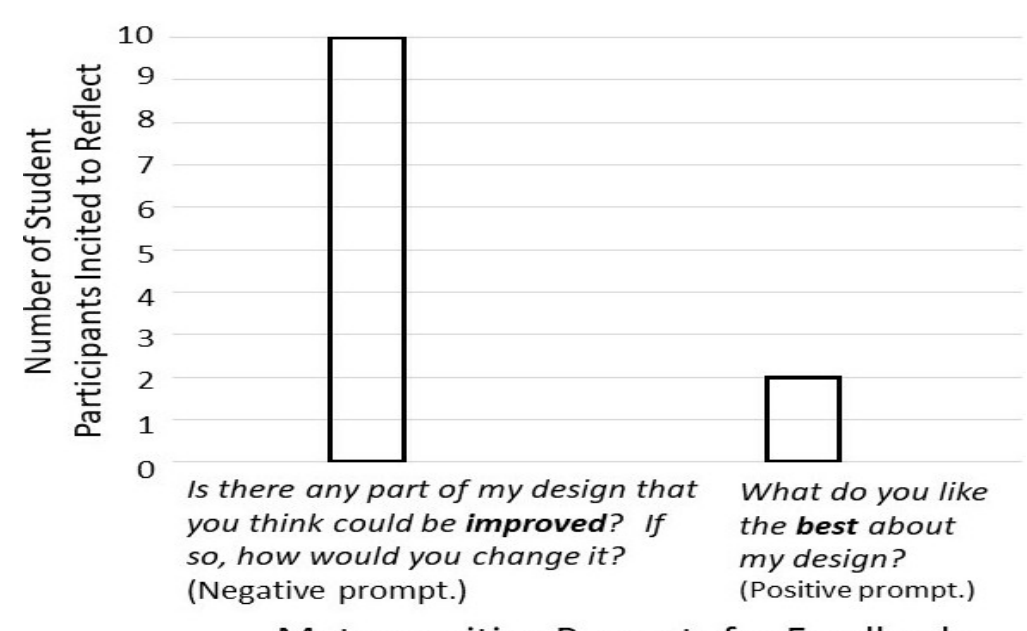

Figure 6. Number of participants who reflected on their partners' designs when prompted for feedback.

The prompts generated peer-to-peer verbal phenomena (e.g., explanations, questions, and feedback). We counted the frequencies of the verbal phenomena and analyzed the counts across all the cases to see if there were any relationships with the numbers of design changes made.

In addition, we examined combinations of verbal phenomena. An "Expressiveness Index" was defined as the sum of all verbal utterances from a participant (excluding the reading of the prompts). Therefore, a participant's Expressiveness Index was the sum of his or her total explanations, feedback given, affirmations given, and questions asked.

Likewise, a "Stimulus Index" was defined as the sum of all the self or partner stimuli given to a participant about his or her design. Thus, a participant's Stimulus Index was the sum of his or her total explanations, feedback received, affirmations received, and questions asked about his or her own design. Plots of the indices versus the number of design changes made are shown in Figures 7. (With the exception of the Olympian and Coach case, the participants in each pair are grouped. Note that participants in a pair are near to each other.) 

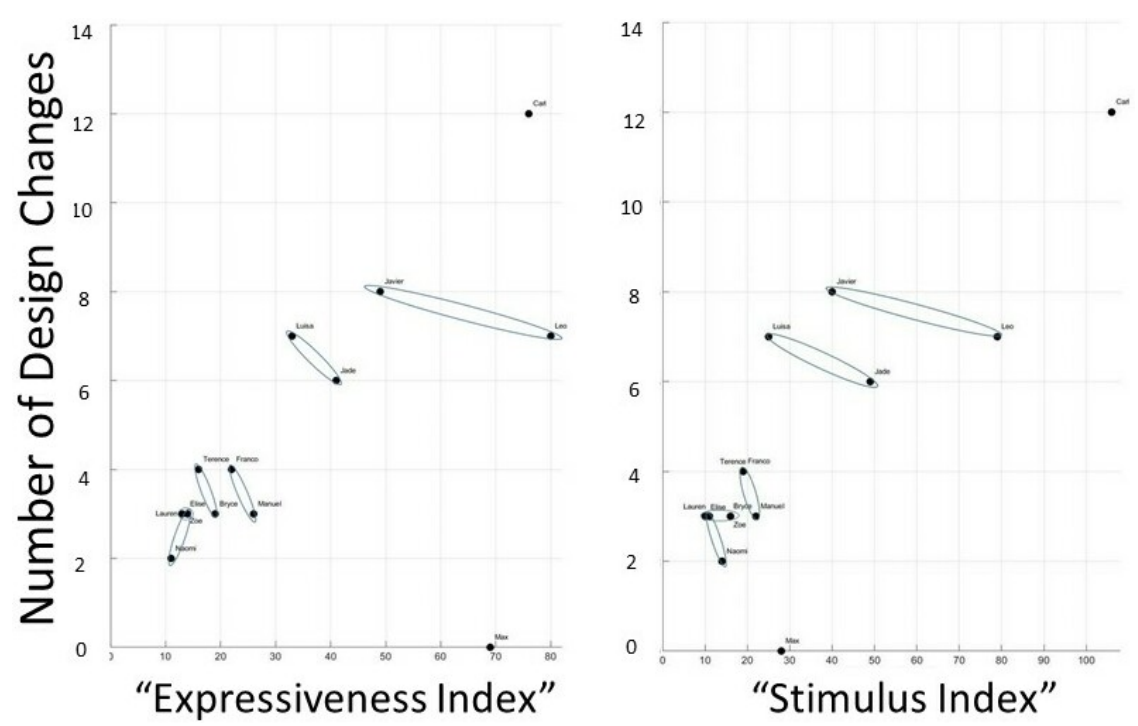

Figure 7. Frequency counts of participants' indices versus design changes.

Excluding the Coach (on the $x$-axis), there was a positive relationship between the Expressiveness and Stimulus Indices and the number of design changes made by participants. Those who were highly verbal and those who received the most stimulus made the most changes.

\section{Peer Interactions}

\section{Conclusions}

Four interaction patterns emerged from the analysis of the case pairs. The metacognitive strategies used by each pair to make design changes depended upon their interaction pattern.

- Guide and Aspirant Interaction Pattern: Design alterations were numerous for both students and came about through a combination of simple explanations, user-centered explanations, feedback, and Guidegenerated questions.

- Supporters Interaction Pattern: Design alterations occurred mostly through a combination of simple and user-centered explanations and feedback.

- Soloists Interaction Pattern: Alterations occurred mostly through simple explanations, a few user-center explanations, and internal (unexpressed) reflection.

- Olympian and Coach Interaction Pattern: Alterations occurred for the Olympian through a combination of simple and user-centered explanations, extensive feedback from the Coach, and Olympian- and 
Coach-generated questions. Alterations were limited to discussions for the Coach and were not explicitly expressed in a sketch.

In addition, for all interaction patterns except the Soloists, there was a socioemotional component to the alterations (Strong, 2018).

\section{Prompts}

The metacognitive prompts that were most effective at inciting the students to reflect upon their designs were the negative ones, which asked about design weaknesses. However, neutral prompts, which asked about how the design worked or how the user would interact with the design, were only slightly less effective than the negative prompts.

\section{Design Changes and Verbal Phenomena}

With the Coach participant excluded, we observed relationships between peer-to-peer verbal phenomena and the number of design changes. There was a strong positive relationship between the amount of feedback that participants received and the number of design changes that they made. There was a weak positive relationship between the number of explanations that participants made and the number of design changes that they made. There was no relationship observed between the number of questions asked and the number of design changes that they made (Strong, 2018).

When combinations of verbal phenomena were analyzed through the Expressiveness and Stimulus Indices, there were positive relationships with the number of design changes. In summary, the students who made the most design changes were the ones who (a) were highly verbal, (b) received the most stimulus about their designs from themselves or from a partner, and (c) were in a Guide and Aspirant pair. This pairing of unsure but motivated students with selfregulated learners had the greatest number of design changes per pair.

\section{Significance for Middle School Educators}

Design is a challenging, creative endeavor. It is a difficult subject to teach because there are no simple algorithms that can manage ill-defined and complex design problems. Nor can simple algorithms handle the nonlinear processes that arise during design, requiring iteration back to earlier stages. Designing requires considerable metacognitive skills to manipulate knowledge - skills that are still under development in adolescence.

This comparative case study demonstrated a pragmatic learning activity for enhancing adolescent designs during their earliest phases through guided peer interactions with metacognitive prompts. Design revision is stimulated through peer-to-peer verbal phenomena and through socioemotional means. Which verbal phenomena contribute to revisions and the degree to which the socioemotional component plays a role depends upon the interaction pattern of 
the paired peers. Educators may choose to let students pair themselves or pair self-regulated learners with more unsure students to create dynamic Guide and Aspirant partnerships. Regardless of how students are paired or their interaction patterns, the learning activity helps adolescents avoid design fixation. Students are stimulated and motivated to alter their designs primarily by creating new criteria or refining or eliminating existing criteria.

The metacognitive prompts used in this comparative case study can be adapted to fit any design challenge. Teachers or instructional designers need only to develop prompts that ask about the user (the one who will be using the design) and what the user's characteristics and needs are. Prompts can then be developed that ask about how the user will interact with the design and why students think their designs will meet the user's needs. Finally, students can be prompted to evaluate a design's strengths and weaknesses - their own and their partner's.

The learning activity used in this study meets the Next Generation Science Standards (NGSS Lead States, 2013) for middle school students which requires sixth through eighth graders to be able to define a problem by specifying criteria and constraints (as was done in the design briefs), develop solutions (as was done in the sketches), and revise. The metacognitive prompts delivered by each student to a peer partner during the learning activity create an environment in which revision is supported both metacognitively and socially. Revision is necessary to emphasize the benefit of peer-prompted engineering design.

\section{References}

Bargh, J. A., \& Schul, Y. (1980). On the cognitive benefits of teaching. Journal of Educational Psychology, 72(5), 593-604. doi:10.1037/00220663.72.5.593

Butler, D. L., \& Winne, P. H. (1995). Feedback and self-regulated learning: A theoretical synthesis. Review of Educational Research, 65(3), 245-281. doi:10.3102/00346543065003245

Casey, B. J., Jones, R. M., \& Hare, T. A. (2008). The adolescent brain. Annals of the New York Academy of Science, 1124(1), 111-126. doi:10.1196/annals.1440.010

Chen, Z.-H., Chou, C.-Y., Deng, Y.-C., \& Chan, T.-W. (2007). Active open learner models as animal companions: Motivating children to learn through interacting with My-Pet and Our-Pet. International Journal of Artificial Intelligence in Education, 17(2), 145-167.

Chi, M. T. H., De Leeuw, N., Chiu, M.-H., \& LaVancher, C. (1994). Eliciting self-explanations improves understanding. Cognitive Science, 18(3), 439477. doi:10.1207/s15516709 $\operatorname{cog} 1803 \_3$

Chin, C., \& Osborne, J. (2008). Students' questions: A potential resource for teaching and learning science. Studies in Science Education, 44(1), 1-39. doi:10.1080/03057260701828101 
Chin, C., \& Osborne, J. (2010). Students' questions and discursive interaction: Their impact on argumentation during collaborative group discussions in science. Journal of Research in Science Teaching, 47(7), 883-908. doi:10.1002/tea.20385

Choi, I., Land, S. M., \& Turgeon, A. J. (2005). Scaffolding peer-questioning strategies to facilitate metacognition during online small group discussion. Instructional Science, 33(5-6), 483-511. doi:10.1007/s11251-005-1277-4

Choudhury, S., Blakemore, S.-J., \& Charman, T. (2006). Social cognitive development during adolescence. Social Cognitive and Affective Neuroscience, 1(3), 165-174. doi:10.1093/scan/ns1024

Choudhury, S., Charman, T., \& Blakemore, S.-J. (2008). Development of the teenage brain. Mind, Brain, and Education, 2(3), 142-147. doi:10.1111/j.1751-228X.2008.00045.x

Christiaans, H., \& Venselaar, K. (2005). Creativity in design engineering and the role of knowledge: Modelling the expert. International Journal of Technology and Design Education, 15(3), 217-236. doi:10.1007/s10798004-1904-4

Cross, N. (2000). Engineering design methods: Strategies for product design (3rd ed.). Chichester, England: Wiley.

Cross, N. (2001). Designerly ways of knowing: Design discipline versus design science. Design Issues, 17(3), 49-55. doi:10.1162/074793601750357196

Cross, N. (2004). Expertise in design: An overview. Design Studies, 25(5), 427441. doi:10.1016/j.destud.2004.06.002

Dorst, K., \& Cross, N. (2001). Creativity in the design process: Co-evolution of problem-solution. Design Studies, 22(5), 425-437. doi:10.1016/S0142694X(01)00009-6

Goldschmidt, G., \& Weil, M. (1998). Contents and structure in design reasoning. Design issues, 14(3), 85-100. doi:10.2307/1511899

Goodrick, D. (2014). Comparative case studies (Methodological Briefs, Impact Evaluation No. 9). Florence, Italy: UNICEF Office of Research. Retrieved from https://www.unicef-irc.org/publications/754-comparative-case-studiesmethodological-briefs-impact-evaluation-no-9.html

Greene, J. A., \& Azevedo, R. (2007). A theoretical review of Winne and Hadwin's model of self-regulated learning: New perspectives and directions. Review of Educational Research, 77(3), 334-372. doi:10.3102/003465430303953

Hruschka, D. J., Schwartz, D., St. John, D. C., Picone-Decaro, E., Jenkins, R. A., \& Carey, J. W. (2004). Reliability in coding open-ended data: Lessons learned from HIV behavioral research. Field methods, 16(3), 307-331. doi: $10.1177 / 1525822 \mathrm{X} 04266540$ 
Ismail, H. N., \& Alexander, J. M. (2005). Learning within scripted and nonscripted peer-tutoring sessions: The Malaysian context. The Journal of Educational Research, 99(2), 67-77. doi:10.3200/JOER.99.2.67-77

Jonassen, D. H. (2000). Toward a design theory of problem solving. Educational Technology: Research \& Development, 48(4), 63-85. doi:10.1007/BF02300500

Katehi, L., Pearson, G., \& Feder, M. (Eds.). (2009). Engineering in K-12 education: Understanding the status and improving the prospects. Washington, DC: National Academies Press. doi:10.17226/12635

King, A., Staffieri, A., \& Adelgais, A. (1998). Mutual peer tutoring: Effects of structuring tutorial interaction to scaffold peer learning. Journal of Educational Psychology, 90(1), 134-152. doi:10.1037/0022-0663.90.1.134

Labuhn, A. S., Zimmerman, B. J., \& Hasselhorn, M. (2010). Enhancing students' self-regulation and mathematics performance: The influence of feedback and self-evaluative standards. Metacognition and Learning, 5(2), 173-194. doi:10.1007/s11409-010-9056-2

Lawanto, O., Butler, D., Cartier, S. C., Santoso, H. B., Goodridge, W., Lawanto, K. N., \& Clark, D. (2013). Pattern of task interpretation and self-regulated learning strategies of high school students and college freshman during an engineering design project. Journal of STEM Education, 14(4), 15-27.

Lawanto, O., Butler, D., Cartier, S., Santoso, H., Lawanto, K., \& Clark, D. (2013). An exploratory study of self-regulated learning strategies in a design project by students in grades 9-12. Design and Technology Education: An International Journal, 18(1), 44-57. Retrieved from https://ojs.lboro.ac.uk/DATE/article/view/1799

Levy, J. S. (2008). Case studies: Types, designs, and logics of inference. Conflict Management and Peace Science, 25(1), 1-18. doi:10.1080/07388940701860318

Lin, X. (2001). Designing metacognitive activities. Educational Technology Research and Development, 49(2), 23-40. doi:10.1007/BF02504926

Luo, Y. (2015). Design fixation and cooperative learning in elementary engineering design project: A case study. International Electronic Journal of Elementary Education, 8(1), 133-145. Retrieved from https://www.iejee.com/index.php/IEJEE/article/view/102

Mawson, B. (2003). Beyond 'the design process': An alternative pedagogy for technology education. International Journal of Technology and Design Education, 13(2), 117-128. doi:10.1023/A:1024186814591

NGSS Lead States. (2013). Next generation science standards: For states, by states. Washington, DC: National Academies Press. doi:10.17226/18290

Patton, M. Q. (1990). Qualitative evaluation and research methods (2nd ed.). Newbury Park, CA: Sage. 
Peteranetz, M. S. (2016). Fostering metacognition in K-12 classrooms: Recommendations for practice. The Nebraska Educator, 3, 64-86. doi:10.13014/K21Z429D

Pintrich, P. R. (2002). The role of metacognitive knowledge in learning, teaching, and assessing. Theory Into Practice, 41(4), 219-225. doi:10.1207/s15430421tip4104_3

Polit, D. F., \& Beck, C. T. (2010). Generalization in quantitative and qualitative research: Myths and strategies. International Journal of Nursing Studies, 47(11), 1451-1458. doi:10.1016/j.jjnurstu.2010.06.004

Roscoe, R. D., \& Chi, M. T. H. (2007). Understanding tutor learning: knowledge-building and knowledge-telling in peer tutors' explanations and questions. Review of Educational Research, 77(4), 534-574. doi:10.3102/0034654307309920

Sheppard, S. D., Macatangay, K., Colby, A., \& Sullivan, W. M. (2009). Educating engineers: Designing for the future of the field. San Francisco, CA: Josey-Bass.

Strong, K. M. (2018). Supporting adolescent metacognition in engineering design through scripted prompts from peer tutors: A comparative case study (Doctoral dissertation). Available from ProQuest Dissertations and Theses database. (UMI No. 10974499)

Topping, K. J. (2005). Trends in peer learning. Educational Psychology, 25(6), 631-645. doi:10.1080/01443410500345172

Vos, H., \& de Graaff, E. (2004). Developing metacognition: A basis for active learning. European Journal of Engineering Education, 29 (4), 543-548. doi:10.1080/03043790410001716257

Wilson, A. A., Smith, E., \& Householder, D. L. (2014). Using disciplinary literacies to enhance adolescents' engineering design activity. Journal of Adolescent \& Adult Literacy, 57(8), 676-686. doi: $10.1002 /$ jaal.302

Yin, R. K. (2009). Case study research: Design and methods (4th ed.). Thousand Oaks, CA: Sage.

\section{About the Authors}

Kristin M. Strong (kristin.strong@aggiemail.usu.edu) was a graduate student in the Department of Engineering Education at Utah State University.

Oenardi Lawanto (olawanto@usu.edu) is Associate Professor in the Department of Engineering Education at Utah State University.

Amy Wilson-Lopez (amy.wilson-lopez@usu.edu) is Associate Professor in the School of Teacher Education and Leadership at Utah State University. 